\title{
Docosahexaenoic acid affects cell signaling by altering lipid rafts
}

\author{
William STILlwell ${ }^{a *}$, Saame Raza SHAIKH ${ }^{\mathrm{a}}$, Mustafa ZEROUGA ${ }^{\mathrm{b}}$, \\ Rafat SIDDIQUI $^{\mathrm{b}}$, Stephen R. WASSALL ${ }^{\mathrm{c}}$ \\ a Department of Biology, Indiana University - Purdue University Indianapolis, \\ 723 West Michigan, Indianapolis, IN 46202, USA \\ b Cellular Biochemistry Laboratory, Methodist Research Institute, Clarian Health Partners, \\ 1801 N. Capitol Ave, Indianapolis, IN 46206, USA \\ c Department of Physics, Indiana University - Purdue University Indianapolis, \\ 402 North Blackford St., Indianapolis, IN 46202, USA
}

(Received 3 January 2005; accepted 2 February 2005)

\begin{abstract}
With 22 carbons and 6 double bonds docosahexaenoic acid (DHA) is the longest and most unsaturated fatty acid commonly found in membranes. It represents the extreme example of a class of important human health promoting agents known as omega-3 fatty acids. DHA is particularly abundant in retinal and brain tissue, often comprising about $50 \%$ of the membrane's total acyl chains. Inadequate amounts of DHA have been linked to a wide variety of abnormalities ranging from visual acuity and learning irregularities to depression and suicide. The molecular mode of action of DHA, while not yet understood, has been the focus of our research. Here we briefly summarize how DHA affects membrane physical properties with an emphasis on membrane signaling domains known as rafts. We report the uptake of DHA into brain phosphatidylethanolamines and the subsequent exclusion of cholesterol from the DHA-rich membranes. We also demonstrate that DHA-induced apoptosis in MDA-MB-231 breast cancer cells is associated with externalization of phosphatidylserine and membrane disruption ("blebbing"). We conclude with a proposal of how DHA incorporation into membranes may control cell biochemistry and physiology.
\end{abstract}

apoptosis / docosahexaenoic acid / lipid rafts / membranes / phospholipids

Abbreviations: DHA: docosahexaenoic acid; DPH: 1,6-diphenylhexatriene; DRM: detergent resistant membranes; DSM: detergent soluble membrane; PC: phosphatidylcholine; PE: phosphatidylethanolamine; PS: phosphatidylserine; PUFA: polyunsaturated fatty acid; SM: sphingomyelin.

\section{INTRODUCTION}

A vast number of health benefits are reputed for docosahexaenoic acid (DHA). If even a small fraction turn out to be true, this simple fatty acid is a most remarkable, perhaps even magical compound. For years we have been investigating possible modes of action for DHA with a goal of discerning what makes it so "special" [1]. A cursory glance of DHA's structure (Fig. 1) would indicate that with 22 carbons and 6 double

* Corresponding author: wstillwe@iupui.edu 
<smiles>CC/C=C\C/C=C\C/C=C\C/C=C\C/C=C\C/C=C\CCC(=O)O</smiles>

Figure 1. Structure of docosahexaenoic acid (DHA, 22:6 $6^{\Delta 4,7,10,13,16,19}$ ).

bonds this molecule is the longest and most unsaturated, and therefore perhaps the most influential, of the omega-3 group of polyunsaturated fatty acids (PUFA) that are classified according to the location of the final double bond relative to the terminal methyl. Here we discuss some of the properties of DHA in the context of its involvement in membranes.

\section{DHA: HEALTH EFFECTS}

A search on DHA and literally any human health problem will generate a plethora of hits. Primarily via the diet, DHA has been reported to have positive effects on an enormous variety of human afflictions including cancer [2, 3], heart disease [4], rheumatoid arthritis [5], asthma [6], lupus [7], alcoholism [8], visual acuity [9], kidney disease [10], respiratory disease [11], peroxisomal disorders (Zellweger's Syndrome) [12], dermatitis [13], psoriasis [14], cystic fibrosis [15], Crohn's Disease [16], schizophrenia [17], depression [18], aggression [191 and brain development [20], malaria [21], multiple sclerosis [22], migraine headaches [23] and even suicide [18]. In fact, it is hard to find any human disorder that has not been tested with DHA. Of particular interest here are the large number of neurological afflictions improved by DHA. The multitude of potential health benefits generates the fundamental question of how one seemingly simple compound can affect so many different processes, and more importantly how this dietary compound can be employed effectively in improving human health.

\section{DHA: POSSIBLE MODES OF ACTION}

Since DHA appears to affect so many different biological systems, it can be assumed that the molecule must be acting at a fundamental level, common to most, perhaps all, cells. Although details of the mode of action remain elusive, five basic themes have emerged. DHA has been shown to affect: hormone (eicosanoid) production [24], formation of potent lipid peroxidation products [25], the conformation and hence activity of specific enzymes [26], transcription events [27], and membrane structure and function $[1,28]$. These general mechanisms are not mutually exclusive. We have concentrated our efforts on how DHA affects membrane structure and function.

\section{DHA: LOCATION \\ IN MEMBRANES}

Numerous dietary and cell culture studies have demonstrated that DHA can be rapidly taken up into cells and incorporated into membrane phospholipids. In mammals, there appear to be two distinctly different paradigms. DHA comprises a major portion of membrane acyl chains (occasionally approaching 50\% [29]) in synaptosomes $[30]$, sperm $[31,32]$ and the retinal rod outer segment [33,34]. Membrane phospholipids have even been identified with DHA in both acyl chains in these specialized cells [35, 36]. Moreover, the already high levels in these membranes are not further augmented by diet and once incorporated, DHA is tenaciously retained at the expense of other fatty acids [29]. One unusual feature of these three high DHA-content membranes is their facility to fuse or exfoliate membrane vesicles ("blebs"). In sharp contrast to the few tissues containing high levels are the other tissues where DHA is often found below $5 \mathrm{~mol} \%$ of the total phospholipid acyl chains. DHA levels in these tissues can be enriched several fold through the diet $[29,37,38]$ and the fatty acid is primarily 
found in the $s n-2$ chain with the $s n-1$ chain mainly composed of the saturated fatty acids palmitic and stearic acid [39, 40].

Incorporation of DHA into phospholipids also varies with the tissue type. In most reported studies DHA has been shown to be primarily esterified to $\mathrm{PE}$ (phosphatidylethanolamine) with lesser amounts to PC (phosphatidylcholine) and other phospholipid classes [38, 41]. For example with T27A leukaemia cells we found DHA initially preferred PE over PC by about 5.7 times [3]. DHA-accumulation into PE, however, is not a fast rule as Salem et al. [29] have reported that in synaptosomal membranes DHA is often found associated with PS (phosphatidylserine). The importance of this observation will be discussed later in the context of DHA's reputed role in inhibiting apoptosis in neuronal tissue. Furthermore, DHA-containing PE has been shown to preferentially accumulate in the inner, (PE- and PS-rich) leaflet of several membranes [41-43].

In a recent diet study on Wistar Rats (Harlan, Indianapolis, IN), we measured the accumulation of DHA into phospholipids isolated from different organs. The rats were fed either a corn oil (omega-6/omega-3, 18:1), a balanced corn oil/fish oil (omega-6/omega$3,1: 1$ ) or fish oil (omega-6/omega-3, 1:3) supplemented diet (Research Diets, Inc., New Brunswick, NJ) for 3 weeks prior to harvesting the organs. Each diet contained similar quantities of protein $(59 \%$ of calories), carbohydrates ( $20 \%$ of calories), lipids ( $21 \%$ of calories), vitamins and minerals. They only differed in the type of supplemented lipid. The acyl chain composition of PS, PC and PE for brain are reported in Table I. Table II presents results comparing the fatty acid content of heart and brain for rats maintained on the fish oil (omega-3rich) diet. As expected, the percent DHA in all phospholipid classes tested increased with the level of DHA in the diet (Tab. I). In brain the percent DHA increased in the order $\mathrm{PC}<<\mathrm{PS}<\mathrm{PE}$ while in the heart the order was altered with PS $<$ PC $<$ PE
Table I. Composition of major fatty acids from phospholipids extracted from the brains of rats fed one of three different diets: corn oil (omega6/omega-3, 18:1), a balanced corn oil/fish oil (omega-6/omega-3, 1:1) or fish oil (omega-6/ omega-3, 1:3) supplemented diet.

\begin{tabular}{lccc}
\hline \multicolumn{5}{c}{ PHOSPHATIDYLSERINE (PS) } \\
\hline \multicolumn{5}{c}{ Corn oil } & $\begin{array}{c}\text { Corn oil/ } \\
\text { fish oil }\end{array}$ & Fish oil \\
$16: 0+18: 0^{1}$ & $51: 0 \pm 4.6^{2}$ & $48.0 \pm 3.0$ & $52.5 \pm 2.6$ \\
$18: 1 \mathrm{n}-9$ & $22.0 \pm 0.7$ & $24 \pm 1.0$ & $17.4 \pm 0.9$ \\
$18: 2 \mathrm{n}-6$ & $3.5 \pm 0$ & $2.0 \pm 0.1$ & $1.4 \pm 0.0$ \\
$20: 4 \mathrm{n}-6$ & $4.5 \pm 0.2$ & $3.5 \pm 0.5$ & $2.8 \pm 0.0$ \\
$22: 6 \mathrm{n}-3$ & $12.0 \pm 0.3$ & $16.5 \pm 0.8$ & $18.3 \pm 1.0$ \\
\hline \multicolumn{5}{c}{ PHOSPHATIDYLCHOLINE (PC) } \\
\hline \multicolumn{5}{c}{ Corn oil } & Corn oil/ & Fish oil \\
16:0 + 18:0 & $48.5 \pm 1.5$ & $50.0 \pm 2.0$ & $53.5 \pm 3.0$ \\
$18: 1 \mathrm{n}-9$ & $24.5 \pm 1.5$ & $22.2 \pm 1.2$ & $21.0 \pm 1.7$ \\
$18: 2 \mathrm{n}-6$ & $3.3 \pm 0.1$ & $2.2 \pm 0.0$ & $1.0 \pm 0.0$ \\
$20: 4 \mathrm{n}-6$ & $4.0 \pm 0.2$ & $4.4 \pm 0.1$ & $4.3 \pm 0.3$ \\
$22: 6 \mathrm{n}-3$ & $3.5 \pm 0.0$ & $4.5 \pm 0.2$ & $4.7 \pm 0.1$ \\
\hline
\end{tabular}

PHOSPHATIDYLETHANOLAMINE (PE)

\begin{tabular}{lrrr}
\hline & Corn oil & $\begin{array}{c}\text { Corn oil/ } \\
\text { fish oil }\end{array}$ & \multicolumn{1}{c}{ Fish oil } \\
$16: 0+18: 0$ & $24.0 \pm 2.5$ & $23.0 \pm 1.8$ & $26.0 \pm 2.0$ \\
$18: 1 \mathrm{n}-9$ & $23.0 \pm 1.0$ & $20.0 \pm 2.0$ & $15.0 \pm 0.7$ \\
$18: 2 \mathrm{n}-6$ & $3.5 \pm 0.5$ & $2.0 \pm 0.0$ & $1.5 \pm 0.3$ \\
$20: 4 \mathrm{n}-6$ & $16.0 \pm 0.8$ & $12.4 \pm 1.0$ & $14.0 \pm 1.5$ \\
$22: 6 \mathrm{n}-3$ & $22.5 \pm 1.6$ & $24.7 \pm 1.8$ & $30.0 \pm 1.2$
\end{tabular}

1 The number before and after the colon represent, respectively, the number of carbons and double bonds in the fatty acid chain.

${ }^{2}$ Expressed as a percentage of total fatty acid esterified to phospholipids species.

(Tab. II). In both tissues PE was the major receptacle for DHA and, in agreement with other reports [29], DHA content in brain PS was enriched relative to heart. 
Table II. Docosahexaenoic acid (DHA) content in phospholipids extracted from the brains and hearts of rats fed a fish oil (omega-6/omega-3, 1:3) supplemented diet.

\begin{tabular}{lccc}
\hline & PS & PC & PE \\
\hline Brain & $18.3 \pm 1.9^{1}$ & $4.7 \pm 0.1$ & $30.0 \pm 1.2$ \\
Heart & $2.4 \pm 0.0$ & $16.6 \pm 1.2$ & $37.0 \pm 0.2$
\end{tabular}

${ }^{1}$ Expressed as a percentage of total fatty acid esterified to phospholipids species.

\section{DHA: PHYSICAL PROPERTIES, AFFECT ON MEMBRANES}

\subsection{Molecular shape}

As a first guess one would probably assume that membranes enriched in DHA with 22 carbons would be very thick. On the contrary, the rod outer segment membrane (where DHA levels approach $50 \%$ of the total acyl chains) is actually quite thin [44]. In agreement, on the basis of ${ }^{2} \mathrm{H}$ NMR order parameters measured for the perdeuterated stearoyl $s n-1$ chain in PCs it was inferred that the thickness of the bilayer is about the same with DHA as stearic acid (18 carbons) at the $s n-2$ position [45]. A wedge shape becoming slightly fatter at the center of the hetroacid saturated-polyunsaturated bilayer is indicated for the saturated chain while, conversely, the DHA chain occupies an inverted wedge shape with higher volume density near the aqueous interface [46]. The origin is the tremendously flexible structure of DHA undergoing rapid inter-conversions between many torsional states such that the terminal methyl end often approaches the membrane surface [47-49]. As a result, the PUFA-containing phospholipid has an increased cross-sectional area and hence exhibits a decreased membrane thickness.

\section{2. "Fluidity"}

A commonly studied membrane parameter is "fluidity". Unfortunately this somewhat conceptual term means different things to different investigators and is often defined by the physical method employed. Also studies on relatively simple, proteinfree lipid bilayer model systems are frequently compared to those from far more complex, heterogeneous biological membranes. As a result contradictory reports of DHA's effect on membrane "fluidity" abound. The most commonly employed method is steady state fluorescence of the probe DPH (1,6-diphenyl hexatriene) that yield polarization values depending upon both the rate of reorientation and degree order of the probe that are combined in the term "fluidity".

High "fluidity" (disorder and rates of molecular reorientation) characterize DHAcontaining membranes by fluorescence polarization of DPH [50-53]. In an illustrative example, Salem and Niebylski [52] made small unilamellar vesicles (SUV) from PCs containing stearic acid $\left(18: 0^{1}\right)$ in the $s n-1$ position and long chain fatty acids with 0 to 6 double bonds in the $s n-2$ position. Steady state fluorescence polarization and time resolved correlation times of DPH were measured. The steady state measurements showed a large increase in "fluidity" upon the addition of the first double bond, a smaller further increase with the second and a still smaller increase in fluidity with up to 4 double bonds. No further increase was measured for DHA with 6 double bonds. However, with time resolved anisotropy they reported a progressive graded decrease in correlation time (increase in "fluidity") for each additional double bond through DHA. The interpretation offered by Salem and Niebylski was that there is an increase in acyl chain free volume with double bonds maximizing at DHA. A similar conclusion was arrived at by Stubbs [51] and by Mitchell and Litman [53].

While only minor contradictions exist concerning the effect of DHA on "fluidity" in model membranes, DHA's effect on the

\footnotetext{
1 The number before and after the colon refers to the number of carbons and double bonds, respectively, in the fatty acyl chain.
} 
"fluidity" of biological membranes is much less certain. Many dietary studies have reported increases in membrane "fluidity" from animals fed DHA-rich fish oil diets $[54,55]$, as well as for cells cultured in DHA-rich media [56-59]. In contrast, some studies did not reveal any significant change in "fluidity" upon incorporation of DHA, despite using the same techniques (primarily steady state polarization of membrane fluorescent probes) that indicated DHA induces an increase in "fluidity" in the other systems [60-63]. For example, Treen et al. [64] were unable to see a difference in "fluidity" (fluorescence polarization of DPH and TMA-DPH) with intact Y-79 retinoblastoma cells cultured in DHA-enriched media despite observing a 4 to 5 fold increase in cellular DHA levels. Employing a different fluorescence method, several reports have indicated DHA does increase "fluidity" as assayed by probes sensing lateral mobility $[60,64,65]$. These observations are consistent with the hypothesis that DHA may play a major role in membrane lateral domain structure (discussed below). The conclusion from these many experiments is that whatever DHA's influence on membrane "fluidity" is, the changes in acyl chain mobility on biological membranes already rich in unsaturated fatty acids are subtle and are less likely to be detectable by measurements with an extrinsic probe of bulk membrane "fluidity" (i.e. steady state fluorescence polarization).

\subsection{Lipid packing and elasticity}

Pressure-area curves for PC monolayer films at the air-water interface demonstrate that, as anticipated, the cross-sectional area generally increases with increasing double bonds and is particularly large in the presence of DHA [66, 67]. The area/molecule for a series of 18:0-XPCs where X represents acyl chains with 0 to 6 double bonds was shown to increase dramatically upon the addition of a first, second and third double bond, but does not change significantly with subsequent double bonds [68]. Inter- estingly this pattern of a large alteration caused by the addition of a first few double bonds but little further change with subsequent double bonds is qualitatively analogous to that reported for "fluidity" as detected by steady state fluorescence depolarization and membrane order as probed by ${ }^{2} \mathrm{H}$ NMR of the perdeuterated $\left[{ }^{2} \mathrm{H}_{35}\right] 18: 0$ $s n-1$ chain [45], and for main melting transition temperature $\left(\mathrm{T}_{\mathrm{m}}\right)$ as measured by DSC (differential scanning calorimetry) [57, 66] and moment analysis of solid state ${ }^{2} \mathrm{H}$ NMR spectra [45].

Another property derived from pressurearea isotherms on lipid monolayers is the lateral compressibility modulus $C_{S}^{-1}$. The measurements indicate that monolayers become more compressible (lower modulus) with increasing number of double bonds [68]. The effect is maximal with DHA. A lower energy requirement to deform a DHA-containing membrane is the implication. Koenig et al. [69] arrived at a similar conclusion using a combined ${ }^{2} \mathrm{H}$ NMR and $\mathrm{X}$-ray diffraction approach on PC bilayers. This elegant method allowed the investigators to simultaneously estimate the compressibility of both the saturated $s n-1$ chain and the unsaturated $s n-2$ chain. The values measured $\left(307 \mathrm{mN} \cdot \mathrm{m}^{-1}\right.$ for stearic acid and $121 \mathrm{mN} \cdot \mathrm{m}^{-1}$ for DHA) establish that the DHA chain is much more compressible than the saturated chain. It was estimated that $75 \%$ of the compressibility of 18:022:6PC could be attributed to the DHA chain. On the other hand, control experiments on 18:0-18:1PC reveal similar compressibility for the saturated and monunsaturated chains. It is predicted that DHA's low compressibility modulus may facilitate structural transitions of certain membrane proteins.

The details of the mechanism by which incorporation of DHA into the various phospholipid types affects membrane protein function is not yet clear. In a review, Mitchell and Litman [26] suggested modulation of three overlapping factors: curvature stress [70, 71], membrane thickness (hydrophobic match) [72] and acyl chain 
packing free volume $\left(f_{V}\right)$ [73]. The packing free volume is of interest here since it is directly related to the tightness of lipid packing. The packing free volume increases with additional double bonds maximizing at DHA. Therefore DHA with its high disorder and associated large cross-sectional area would be expected to pack poorly with other membrane lipids. For more than a decade Litman and Mitchell [26] have studied the effect of DHA on the visual process, particularly the rhodopsin $\mathrm{M}_{\mathrm{I}}$ to $\mathrm{M}_{\mathrm{II}}$ conformational transition [74]. The transition was shown to be dependent on lipid type, favoring lipids with small head groups and wide acyl tails (i.e. DHA-rich PCs). In general, hexagonal phase-preferring lipids possessing high elastic curvature stress favor the $\mathrm{M}_{\mathrm{II}}$ conformation [75]. In their $\mathrm{M}_{\mathrm{I}}$ to $\mathrm{M}_{\mathrm{II}}$ rhodopsin model Mitchell and Litman $[26,74,76]$ found the packing free volume and $\mathrm{M}_{\mathrm{II}}$ formation increased in the order 16:0-18:1PC < 16:0-22:6PC < 22:6-22:6PC. It is not yet clear the relationship between elasticity, packing free volume and protein activity for the vast majority of membrane proteins.

\subsection{Permeability}

It stands to reason that membranes whose lipids are poorly packed should also be highly permeable and indeed there have been numerous reports linking DHA to increases in membrane permeability. In an early report, Hendriks et al. [77] showed that vesicles made from lipid extracts of rod outer segment membranes (DHA-rich) were 10 times more permeable to ${ }^{22} \mathrm{Na}^{+}$than were vesicles made from lipids extracted from other (DHA-poor) retinal membranes. Demel et al. [78] demonstrated that DHA incorporated into the $s n-2$ position of PC enhanced permeability to glucose, erythritol and glycerol. Measuring bilayer permeability to erythritol and carboxyfluorescein, Stillwell et al. [79] established that DHA enhanced bilayer permeability 2 to 3 fold more than oleic acid in identical phospholipids. Huster et al. [80] used ${ }^{17} \mathrm{O}$ NMR to follow water permeability across lipid bilayers. They determined that 18:0-22:6PC membranes are about $4 \times$ more permeable than those made of 18:0-18:1PC but are about $30 \%$ less permeable than those of 22:6-22:6PC. As a result of increased water penetration, DHA favors increased hydration of the head group and inter-chain region. In agreement, fluorescence measurements on lipid bilayers confirmed that water content in the bilayer hydrocarbon region increases with double bond content [53]. Increases in mitochondrial permeability have also been linked to DHA content $[65,81]$. The resultant proton leakage in turn decimates the essential trans-membrane $\mathrm{H}^{+}$gradients, an event linked to mitochondrial-linked apoptosis [82] (see below).

\subsection{Bilayer instability: vesicle fusion, exfoliation and flip-flop}

The loose packing of DHA-containing phospholipids implies that high levels of this fatty acid may also lead to general membrane instability resulting in enhanced vesicle exfoliation ("blebs"), fusion and flip-flop. Perhaps not coincidentally, biological membranes that are naturally enriched in DHA (neuronal synaptosomes, rod outer segments and sperm) are partly characterized by their predisposition to undergo membrane vesicle formation and fusion. Ahkong et al. [83] and later Meers et al. [84] showed that PUFA promote the fusion of natural membranes. In a series of studies Stillwell and Jenski have fused DHA-containing phospholipid vesicles with several types of membranes and monitored the effect of fusion-augmented DHA levels on bilayer membrane [85], mitochondria [65] and T27A cell properties [3, 86-89]. DHA as either the free fatty acid or as part of a mixed chain PC (18:0-22:6PC) enhanced SUV fusion to a much larger extent than did PCs with other, less unsaturated fatty acids [85]. When T27A tumor cells were fused with vesicles containing 18:0-22:6PC, the tumor plasma membrane became leakier 
[79], had altered expression of surface proteins [89], altered domain structure [90], decreased cell deformability [91], increased cytolysis by cytotoxic T-lymphocytes [86] and decreased cell longevity [3, 89]. Upon fusion with SUVs made from 18:0-XPC, where $\mathrm{X}$ is stearic, oleic, $\alpha$-linolenic, arachidonic, eicosapentaenoic or DHA, only DHA was cytotoxic [88]. It is now well documented that membrane fusion is enhanced by the presence of lipids, like DHA, that promote inverted hexagonal phase and thus provide curvature stress to membranes [92].

Since exfoliation is the reverse of fusion, Williams et al. [93] isolated exfoliated vesicles (EV) from DHA-enriched T27A cells and measured their lipid content (phospholipid class, fatty acid, and cholesterol) and membrane molecular order. A comparison of these values between the DHA-induced exfoliated vesicles (EVs) and the parent plasma membrane led these authors to conclude that EV composition and structure was considerably different than that of the parent plasma membrane. After incubation in the presence of DHA, EVs exhibited higher levels of DHA and lower levels of cholesterol. Also fluorescence anisotropy of DPH, PA-DPH and TMA-DPH decreased, indicating a DHA-induced increase in membrane "fluidity" in the EVs. These results imply that DHA-driven microdomains are either large enough or numerous enough to influence a sizable portion of T27A membrane surface and that EVs reflect plasma membrane lipid domains.

Recently Armstrong et al. [94] employed fluorescence quenching of NBD-PE probes to monitor the effect of PC acyl chain double bond content on trans-membrane flipflop. This study demonstrated that as the number of double bonds increases, so does the flip-flop rate of the NBD-PE probes. The increase was particularly marked in the presence of DHA. A half-life $t_{1 / 2}$ of $0.086 \mathrm{~h}$ was reported for bilayers composed of 22:6-22:6PC and $0.29 \mathrm{~h}$ for 18:0-22:6PC, whereas 18:0-18:1PC exhibited a much slower flip-flop of $t_{1 / 2}=11.5 \mathrm{~h}$. These authors concluded that PC membranes containing DHA support very fast flip-flop rates [94].

\section{MEMBRANE STRUCTURE AND RAFTS}

The structure of biological membranes remains one of the most difficult problems in the life sciences [95-97]. Since membrane structure was first described by the Fluid Mosaic Model in 1971 [98], it has become evident that membranes consist of very complex heterogeneous lipid and protein patches that are in constant flux and so far have been recalcitrant to precise analysis. For the past decade the concept of lipid rafts has been a focus of membrane research [97, 99].

Lipid rafts are liquid ordered, sphingomyelin (SM)-rich/cholesterol-rich microdomains that are postulated to serve as platforms for protein activity by accumulating specific lipidated proteins such as the src family of kinases in the inner leaflet and GPIanchored proteins in the outer leaflet of plasma membranes [97, 99, 100]. The rafts are floating in a sea of liquid disordered, SM-poor/cholesterol-poor microdomains that must have its own array of proteins. In fact it is likely that numerous proteins may migrate between domains in response to alterations in lipid composition. Historically their resistance to dissolution in cold temperature detergents, particularly Triton $\mathrm{X}-100$, has defined lipid rafts. While detergent resistant membranes (DRMs) mark the beginnings of raft studies, they are wrought with artifacts and are being replaced by gentler, detergent-free methods. Our initial guess was that DHA-phospholipids, being very "fluid" should accumulate in the detergent-soluble membrane (DSM) fractions and indeed, this is the case (Fig. 2). The question can then be posed, does DHA incorporation actually affect membrane architecture and if so how? 


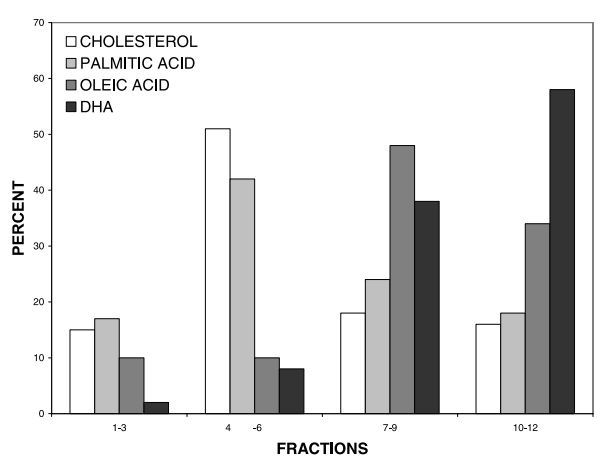

Figure 2. Fractionation of MDA-MB-231 breast cancer cells grown in culture with various radiolabeled lipids. The cells were disrupted in $1 \%$ Triton X-100 at $4{ }^{\circ} \mathrm{C}$ and incubated for 30 min after which the fractions were separated on a sucrose gradient by standard procedures [171]. Radioactive counts were determined for each of the 12 fractions. For ease of presentation fractions $1-5,4-6,7-9$ and $10-12$ were combined. The detergent-resistant rafts are in fractions 4-6. Cholesterol and palmitic acid are primarily found in the raft fractions while DHA is primarily found in the non-raft fractions 7-9 and 10-12.

\section{DHA: INTERACTION WITH RAFT LIPIDS (CHOLESTEROL AND SPHINGOMYELIN)}

One molecule seems to be at the heart of understanding the structure and function (and even existence!) of rafts - cholesterol. For many years it has been known that the major lipid comprising the plasma membrane of most animal cells is cholesterol and the primary role of the sterol is to modulate the physical properties of membranes [101]. The situation is well-documented in membranes composed of saturated acyl chains [101], but is far less understood in DHAcontaining membranes. Upon its incorporation into cells, DHA is incorporated into membranes where it must be exposed to cholesterol and the interaction between these two species may profoundly affect membrane structure and function. This has been the premise of our research.
Early experiments showed that DHAcontaining PCs were far less affected by cholesterol than were many other PCs [101, 102]. They showed that cholesterol demonstrated little monolayer "condensation" and had little effect on bilayer permeability of DHA-containing PCs compared to less unsaturated PC [78, 103, 104]. Using pressure-area techniques on monolayers, Smaby et al. [68] measured elasticity compression moduli for various PCs. The in-plane elasticity moduli of the PC species with higher $s n$-2 double bond content were found to be less affected by increased levels of cholesterol. Their work predicts that cholesterolunsaturated fatty acid interaction results in localized regions in membranes that differ considerably in their in-plane elasticity. Partition coefficients $\left(K_{A}^{B}\right)$ determined for cholesterol in unilamellar vesicles by a cyclodextrin assay follow the order 18:018:1PC > 18:1-18:1PC > 18:2-18:2PC > 16:0-22:6PC > 22:6-22:6PC [105]. Mitchell and Litman $[26,73]$ have employed a model system monitoring the effect of acyl chain packing free volume $\left(f_{V}\right)$ on the $\mathrm{M}_{\mathrm{I}}$ to $\mathrm{M}_{\mathrm{II}}$ equilibrium $\left(\mathrm{K}_{\mathrm{eq}}\right)$ of rhodopsin to determine the effect of cholesterol on a protein's function in a DHA-rich membrane. They incorporated rhodopsin into LUV made from $22: 6-22: 6 \mathrm{PC} ; 16: 0-22: 6 \mathrm{PC}$ or $16: 0-$ $18: 1 \mathrm{PC}$ with or without $30 \%$ cholesterol. Without cholesterol $\mathrm{K}_{\mathrm{eq}}$ and $\mathrm{f}_{\mathrm{v}}$ increased in the order: 16:0-18:1PC < 16:0-22:6PC < 22:6-22:6PC. Cholesterol reduced these values in the order: $16: 0-18: 1 \mathrm{PC}>16: 0$ 22:6PC $>22: 6-22: 6 \mathrm{PC}$. Their results suggest that regulation of an integral membrane receptor (rhodopsin) function may be metabolically controlled by changes in phospholipid acyl chain composition and/or cholesterol content. They propose a primary role for phospholipid and a secondary role for cholesterol [73].

DSC has been extensively employed to investigate cholesterol-phospholipid interactions. Many DSC experiments have demonstrated that cholesterol induces phase separations in PC bilayers [1, 102, 106, 107]. The addition of up to $50 \mathrm{~mol} \%$ cholesterol 
to $22: 6-22: 6 \mathrm{PC}$ has little impact upon the temperature or enthalpy of the gel-to-liquid phase transition [108], whereas with 16:0$18: 1 \mathrm{PC}$ or $16: 0-22: 6 \mathrm{PC}$ the transition is eliminated by $\geq 35 \mathrm{~mol} \%$ cholesterol [109]. Regardless of unsaturation, the response to incorporation of cholesterol is a disruption of acyl chain packing in the organized gel state while in the fluid liquid crystalline state acyl chain motion is restricted [110112] (i.e. cholesterol increases the "fluidity" of solid membranes while decreasing the "fluidity" of fluid membranes).

The implication of the biophysical studies outlined above is that the solubility of cholesterol in phospholipid membranes may be dependent on double bond content. Recently we have directly tested this hypothesis using a combination of solid state ${ }^{2} \mathrm{H}$ NMR spectroscopy and XRD (X-ray diffraction) [113-116]. The NMR technique identifies a narrow spectral component due to cholesterol incorporation into the membrane superimposed upon a broad component from solid crystalline monohydrate cholesterol form outside the membrane. The XRD technique relies upon the detection of diffraction peaks from cholesterol monohydrate crystals excluded from the membrane once the solubility limit is exceeded. Both methods established that when forced to interact with PUFA chains in $s n-1, s n-2$ dipolyunsaturated PC membranes, cholesterol precipitates out of the membrane at concentrations of a factor of 3-5 less than in the corresponding $s n-1$, $s n-2$ saturated-polyunsaturated membrane where close proximity to the PUFA chain may be avoided. Profoundly reduced affinity of the sterol for PUFA was thus quantified. It is the extraordinarily high disorder of PUFA chains that we propose on steric grounds is incompatible with near approach from the rigid steroid moiety.

In companion ${ }^{2} \mathrm{H}$ NMR experiments we measured the most probable orientation (tilt angle) for $\left[3 \mathrm{a}^{2}{ }^{2} \mathrm{H}_{1}\right]$ cholesterol in bilayers composed of various PCs and PEs [113$115,118]$. We discovered that, irrespective of the degree of $s n$ - 2 chain unsaturation, the tilt angle $\left(\alpha_{0}=16^{\circ}\right)$ was the same for all the hetero-acid phospholipids studied with a saturated $s n-1$ chain. Only for dipolyunsaturated phospholipids with DHA or 20:4 acid at both $s n-1$ and -2 positions was the value substantially greater $\left(\alpha_{0}=24^{\circ}\right)$. Our interpretation is that cholesterol will laterally organize within membranes to minimize contact with a DHA $s n-2$ chain and preferentially associate with a saturated $s n-1$ chain. Others have made the same proposal $[53,73]$, and both experimental [80] and computer simulated [118] data lend further support.

The interaction of cholesterol with DHAcontaining PEs has received much less attention than with the equivalent PCs. Early DSC studies found that cholesterollipid interaction follows the following sequence: $\mathrm{SM}>>$ PS, PG > PC $>>$ PE [119]. In agreement, by a cyclodextrin assay Niu and Litman [105] determined partition coefficients in the order SM > PS > PC > $\mathrm{PE}$ for cholesterol in unilamellar vesicles. Although most PE localizes to the inner leaflet, nearly $17 \%$ is outer leaflet and so should directly act on rafts [120]. Also PE is the major receptacle of DHA in most membranes. In Table III we compare cholesterol solubility in $s n-1$ saturated, $s n-2$ unsaturated PE and PC bilayers with 18:1 acid or DHA at the $s n-2$ position. The

Table III. Solubility of cholesterol in PEs obtained from XRD measurements. Values for PCs are included for purposes of comparison. Samples were in the lamellar liquid crystalline state.

\begin{tabular}{lccc}
\hline PE & $\begin{array}{c}\text { Cholesterol } \\
\text { solubility } \\
\text { mol\% }\end{array}$ & PC & $\begin{array}{c}\text { Cholesterol } \\
\text { solubility } \\
\text { mol\% }\end{array}$ \\
\hline $16: 0-18: 1$ & $51 \pm 3^{1}$ & $16: 0-18: 1$ & $65 \pm 3^{3}$ \\
$16: 0-22: 6$ & $31 \pm 3^{2}$ & $18: 0-22: 6$ & $55 \pm 3^{4}$ \\
\hline $140^{\circ} \mathrm{C}$, value taken from Shaikh et al. [116]. \\
$27.5^{\circ} \mathrm{C}$, value taken from Shaikh et al. [116]. \\
$324^{\circ} \mathrm{C}$, value taken from Huang et al. [170]. \\
$420^{\circ} \mathrm{C}$, value taken from Brzustowicz et al. [114].
\end{tabular}


results demonstrate that there is a greater DHA-associated reduction in solubility for PE than for PC bilayers, which we attribute to its smaller headgroup [116].

\section{DHA AND MEMBRANE DOMAINS}

Although details have not been forthcoming, it has been known for a long time that lipid-lipid interactions must play an active role in organizing membranes into domains [1, 121]. We [104, 115-117, 122] and others [74, 111, 123] have shown that a reduced affinity between cholesterol and polyunsaturated fatty acids may drive lateral phase separation into cholesterol-rich/ PUFA-poor and cholesterol-poor/PUFA-rich membrane microdomains.

There have been a few examples of DHAinduced lipid phase separations described for model bilayer membranes. Stillwell et al. $[28,90]$ have demonstrated that bilayers composed of 16:0-16:0PC and 18:022:6PC can phase separate. Niebylski and Litman [124] employed fluorescence probes to show that bilayers composed of 16:0-16:0PC and 22:6, 22:6PC phase separate. While both of these reports clearly establish the formation of DHA-enriched domains in model membranes, each suffers from the same shortcoming. They are examples of liquid crystalline/gel separations. What are needed are biologically relevant fluid/fluid (liquid ordered/liquid disordered) separations. For this reason, Stillwell et al. $[1,28]$ have looked for fluid/fluid phase separation in more biologically relevant bilayer model membranes composed of either PCs or PEs with palmitic or stearic acid in the $s n-1$ position and DHA in the $s n-2$ position mixed with the raft lipids SM and cholesterol. Surface elasticity measurements on monolayers, and DSC, detergent extraction and solid state ${ }^{2} \mathrm{H}$ NMR measurements on bilayers support the idea that DHA-containing phospholipids enhance the lateral segregation of cholesterol into sterol-rich/ SM-rich liquid ordered regions away from sterol-poor/DHA-PE- or DHA-PC-rich liq- uid disordered domains [117, 122, 125]. Estimates of the size of PUFA-induced domains are small. From an analysis of ${ }^{2} \mathrm{H}$ NMR spectra, an upper limit of $\sim 160 \AA$ was placed on microdomain size in 18:020:4PC/20:4-20:4PC/cholesterol (1/1/2 mol) [115]. A comparable estimate $(\leq 250 \AA)$ for microdomains produced by cholesteroltriggered segregation in 18:0-22:6PC/18:022:6PE/18:0-22:6PS $(4 / 4 / 1 \mathrm{~mol} / \mathrm{mol} / \mathrm{mol})$ membranes was deduced on the basis of NMR data by Huster et al. [80]. These values are much less than that typically quoted for lipid rafts ( $\geq 50 \mathrm{~nm}$ ). As raft studies continue to evolve, however, the estimated raft size in biological membranes continues to decrease, making their direct observation less likely [96].

Indirect observations supporting an effect of DHA on lateral organization within membranes are abundant. For example, Clamp et al. [60] reported there is greater interdomain variation in hepatocyte plasma membranes from rats maintained on a fish oil diet. Jenski et al. [126] added DHA to cultured splenic lymphocytes or lymphoma cells and measured fatty acid uptake and membrane structure alteration (protein clustering). Protein clustering rate (determined by fluorescence resonance energy transfer between fluorophore-labeled antibodies bound to membrane proteins) was 2-fold higher in DHA-rich than DHA-poor cells. Williams et al. [93] isolated exfoliated vesicles (EV) from DHA-enriched T27A cells and measured their lipid content (phospholipid class, fatty acid, and cholesterol) and membrane "fluidity". A comparison of these values between the DHA-induced EVs and the parent plasma membrane led these authors to conclude that EV composition and structure was considerably different than that of the plasma membrane implying that DHAdriven microdomains are either large enough or numerous enough to influence a sizable portion of T27A membrane surface and that EVs reflect plasma membrane lipid domains. These are but a few examples of many that indicate DHA may affect membrane structure and hence function. 
The best studied DHA-membrane system is the rhodopsin model of Litman and Mitchell [26, 73, 74, 76]. Their model is based on strong interactions between the saturated $s n-1$ chain of PCs containing DHA in the $s n-2$ position. The $s n-1$ chains are oriented towards the tightly packed domain interior with the $s n-2$ chains oriented toward the domain boundary [73]. The DHA-rich $s n$ - 2 chain is proposed to primarily determine the lateral packing of the system that is responsible for the $\mathrm{M}_{\mathrm{I}}$ to $\mathrm{M}_{\mathrm{II}}$ equilibrium. Cholesterol partitions into the saturated chain-rich domain interior where it reduces the acyl chain packing free volume. This model also predicts that 22:622:6PC will pack between the domains to maintain maximal saturated chain interactions. Therefore, there are two levels of interaction in the Litman/Mitchell model, primary regulation of rhodopsin by acyl chain composition and a secondary regulation by cholesterol content. In model membrane studies it was reported that coexisting 16:0-16:0PC and 22:6-22:6PC lateral domains were found only when both cholesterol and rhodopsin were also included and that the protein was preferentially enriched into 22:6-22:6PC domains about $6 \times$ greater than into 16:0-16:0PC domains [127]. Furthermore it was proposed by Litman et al. [128] that DHA-containing phospholipids can buffer the inhibitory effects of cholesterol in the visual receptor signalling pathway.

We have recently begun an AFM (atomic force microscopy) study of the effect of DHA on raft structure [125]. Our very initial imaging studies compared bilayers composed of either 16:0, 18:1 PE/SM/cholesterol $(1: 1: 1)$ or 16:0, 22:6 PE/SM/cholesterol $(1: 1: 1)$. Large differences in raft (SM/cholesterol-rich) domains were readily detected between the two systems. Raft domains comprised $26 \pm 2 \%$ of the 16:0, 18:1 PE/SM/cholesterol membrane and $59 \pm$ $10 \%$ of the 16:0, 22:6 PE/SM/cholesterol membrane indicating that DHA drives greater phase separation than does oleic acid. Also the individual domains observed in the PUFA-containing membrane were much bigger and connected compared to those observed in the oleic acid-containing membrane.

While lateral phase separation has been the focus of most lipid microdomain (raft) studies, biological membranes also exhibit substantial trans-bilayer heterogeneity. It is well documented that highly unsaturated species of PE and PS are found primarily on the inner leaflet of many membranes [29, 43,129 ] including murine synaptosomal plasma membranes [130]. However DHA distribution is not absolute as rats fed a fish oil diet exhibited an increase in DHA-containing species of PC in the outer leaflet of erythrocyte membranes [131]. It was proposed that membrane enrichment of PUFA might result in relocation of acylated raft proteins between raft and non-raft domains.

Addition of PUFA to membranes has also been shown to alter trans-bilayer sterol localization $[132,133]$. Although the transmembrane distribution of cholesterol is not known with absolute certainty [134, 135], the outer leaflet of plasma membranes may contain more cholesterol and therefore be more rigid than the inner leaflet. This is consistent with the current idea of cholesteroland sphingolipid-rich lipid rafts residing in membrane outer leaflets [100]. Also, it is known that cholesterol has a higher affinity for sphingolipids than for other common membrane lipids [120, 136, 137] and sphingolipids clearly are primarily located in the outer leaflet [100]. However, very rapid cholesterol flip-flop [138, 139] makes precise cholesterol asymmetry measurements difficult. Upon addition of PUFA in culture, a decrease in molecular order and a redistribution of cholesterol with more than $70 \%$ going to the outer leaflet was reported by Schroeder and co-workers [132, 133]. Dusserre et al. [140] reported cholesterol efflux from plasma membranes remained the same after incorporation of oleate, linoleate or arachidonate but increased with EPA and DHA. They suggested that incorporation of DHA into the membrane inner leaflet forces 
cholesterol into outer leaflet where it is more readily lost from the membrane.

\section{DHA: AFFECT ON CELL SIGNALING AND APOPTOSIS}

At present there is a large and ever expanding list of proteins whose activities have been shown to be affected by DHA. The most thoroughly studied of the proteins by far has been rhodopsin (see discussion above) $[26,73,74)$. The important signaling protein, $\mathrm{PKC}$ (protein kinase $\mathrm{C}$ ) has also been shown to be activated by fatty acids like DHA that exhibit large negative curvature stress [141-143]. In one example, Giorgione et al. [144] found that DHA acyl chains produced the highest level of PKC activity when incorporated into PE but not into PC and the activity was correlated with increased partitioning of PKC into the membrane. Their results indicate that the formation of membrane domains can be important for the activation of PKC and, furthermore, the activation can be inhibited by disrupting the domains.

Since nervous tissue is known to be highly enriched in DHA [29], it was logical to investigate the effect of this fatty acid on channel activity. Using patch clamp techniques, Poling et al. $[145,146]$ reported that non-esterified DHA interacts with an external channel domain and regulates the activity of certain voltage-gated $\mathrm{K}^{+}$channels in a $\mathrm{Zn}^{2+}$-dependent fashion. PUFA have additionally been shown to modulate L-type $\mathrm{Ca}^{2+}$ channels [147, 148], suggesting a role in cell signaling. Hasler et al. [149] reported that $50 \mu \mathrm{M}$ DHA inhibited gap junction intercellular communication by $18 \%$ while several other fatty acids had no measurable effect. Finally, Jenski et al. have studied the expression of MHC I molecules as modified by DHA. They demonstrated altered expression of MHC I, CD8, and CD90 (Thy-1) on murine lymphocytes and leukemia cells enriched in DHA through diet or cell culture [89, 150]. These are but a few of a wide variety of reports linking DHA to cell signaling events through membrane alteration.

The effect of DHA on apoptosis or programmed cell death has received considerable scrutiny. It is well established that many events associated with apoptosis are linked to membrane structure and function [151]. For example, externalization of PS to the outer leaflet of the plasma membrane $[152,153]$ and formation of "blebs" [154] are considered hallmarks of apoptosis. However, there remains a distinct dichotomy of opinions concerning whether DHA enhances or inhibits apoptosis.

The preponderence of reports coming from a vide variety of primarily cancer cell types [155-159] indicate that DHA induces apoptosis and it has been suggested that DHA's anticancer properties are not due directly to cytotoxicity, but rather to the fatty acid's ability to induce apoptosis [160-162]. Siddiqui et al. [163] have recently reviewed the role of DHA in enhancing both the cytosol-linked and mitochondrial-linked apoptotic pathways. We [164] have compared the effect of DHA on breast cancer cell proliferation in vivo (in nude mice, nu/ nu) and in vitro (cultured MDA-MB-231 cells). We reported that DHA caused a profound inhibition of cancer cell growth and increased apoptosis. Associated with this was an increase in N-SMYase activity (by $\sim 40 \%$ ) in the breast cancer tissues from mice raised on the omega- 3 containing diets and by $70-75 \%(P<0.05)$ in the MDA cells that had been treated with DHA. The DHAinduced increase in N-SMYase activity was further analyzed by formation of ceramide, the product of sphingomyelin hydrolysis. Ceramide is a lipid that is regarded as a universal component of apoptosis $[165,166]$. We have also reported extensive DHAinduced "blebbing" of the tumor cell membranes (Fig. 3a) and appearance of PS on the outer membrane surface (Fig. 3b), both strong indicators of apoptosis. In addition, DHA-induced apoptosis and "bleb" formation was inhibited $(\sim 40 \%)$ by the N-SMYase inhibitor GW4869. The conclusion of these experiments was that inhibition of breast 
a

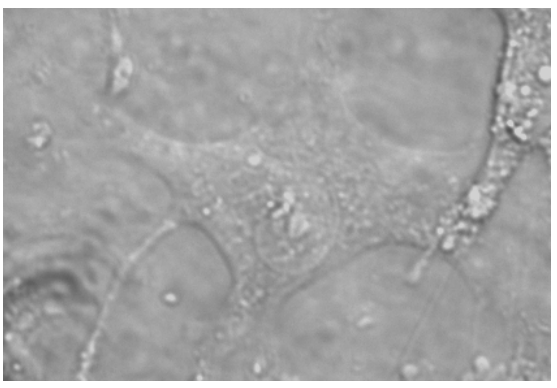

Control

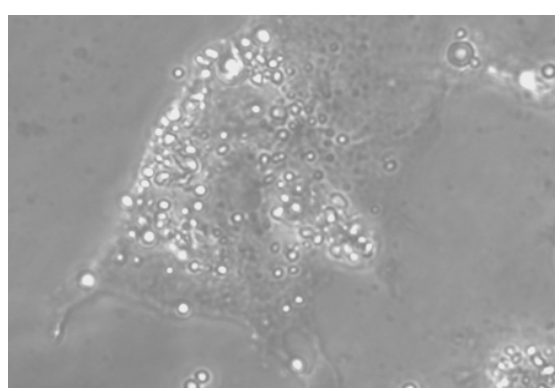

$20 \mu$ M DHA

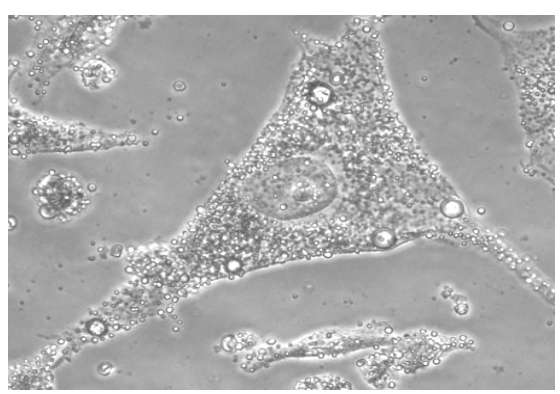

$50 \mu$ M DHA

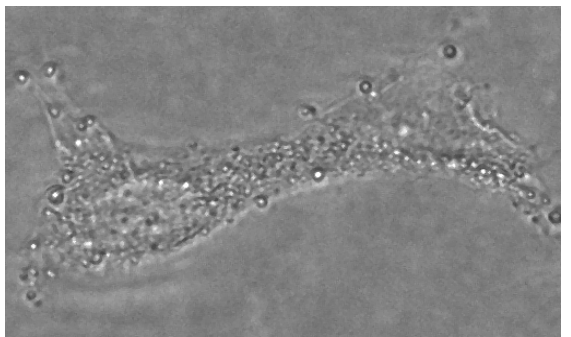

\section{Bright Light}

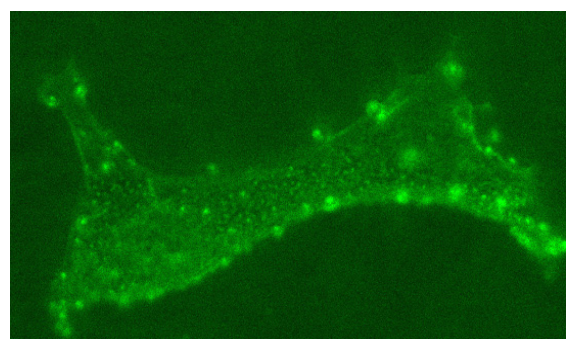

II. Annexin-V staining

Figure 3. MDA-MB-231 cells were cultured in the presence of various concentrations of DHA (a). DHA-dependent "blebs" were observed under a microscope using a $40 \mathrm{X}$ objective. The "blebs" from cells grown in $50 \mu \mathrm{M}$ DHA were analyzed for externalized PS using a fluorescent annexin binding kit (b).

cancer growth in nude mice by fish oil or in culture by treatment with DHA appear to be mediated by generation of ceramide through enhanced N-SMYase activity.
In sharp contrast to the many reports demonstrating that DHA induces apoptosis are fewer reports, usually on neuronal cells, indicating that DHA actually inhibits apoptosis 
[167-169]. Kim and coworkers have reported that DHA inhibits serum deprived- [168] and stautosporine-induced [167] apoptosis in mouse neuroblastoma Neuro 2A cells using the very same assays (cleavage of procaspase-3, DNA laddering etc.) others have used to demonstrate that DHA induces apoptosis. Clearly there is a discrepancy between the affect of DHA on neuronal vs. other types of cells. Kim [168] explains this in terms of DHA increasing the PS content in membranes of neuronal cells. However increased PS levels would enhance the chance of PS appearing in the membrane outer leaflet, a well-established trigger for apoptosis [152, 153]. Also it has been demonstrated that increasing the DHA content of membranes substantially increases phospholipids flipflop [94], again increasing the likelihood of moving PS to the outer leaflet. The important relationship between DHA and apoptosis will require far more study.

\section{CONCLUSIONS}

There is abundant evidence that DHA can be rapidly accumulated into membrane phospholipids and there, potentially affect a variety of membrane physical properties including: membrane thickness, lipid packing, "fluidity", elasticity, permeability, flipflop, protein activity, fusion, "blebbing" and the structure and function of lateral and trans-membrane heterogeneities (domains) [1]. The implication of many diverse observations, moreover, is that membrane perturbations are either the cause or the result of apoptosis. Thus, it is interesting to note many of the membrane properties that change during apoptosis are similar to those that change upon accumulation of DHA into membranes. Our focus has been on the affect of DHA on one important and very controversial type of membrane domain, the cell signaling lipid raft.

We hypothesize that DHA is incorporated mainly into PEs (primarily in the membrane inner leaflet) and secondarily into PCs (primarily in the membrane outer leaflet). It is DHA's aversion to cholesterol that will segregate the DHA-containing phospholipids away from cholesterol, resulting in enhanced phase separation into DHArich/cholesterol and sphingolipid-poor liquid disordered (non-raft) domains and cholesterol and sphingolipid-rich/DHA-poor liquid ordered (raft) domains. The large difference in physical properties between the two domains will alter the membrane location of important signaling proteins, thus modulating cellular functions. Also accumulation of DHA into inner leaflet PEs will enhance cholesterol's flip-flop to the outer leaflet where its increased concentration would further add to the size and stability of rafts. In support of an enhancement of cholesterol flip-flop, Dusserre et al. [140] reported that cholesterol efflux from plasma membranes increased with DHA.

We conclude that although the mechanism of action of DHA is likely multifaceted, one major function is its affect on membrane structure and function.

\section{REFERENCES}

[1] Stillwell W, Wassall SR. Docosahexaenoic acid: Membrane properties of a unique fatty acid. Chem Phys Lipids 2003, 126: 1-27.

[2] Carroll KK. Dietary fats and cancer. Am J Clin Nutr 1991, 53: 1064S-1067S.

[3] Zerouga M, Stillwell W, Stone J, Powner A, Dumaual AC, Jenski LJ. Phospholipid class as a determinant in docosahexaenoic acid's effect on tumor cell viability. Anticancer Res 1996, 16: 2863-2868.

[4] McLennan P, Howe P, Abeywardena M, Muggli R, Raederstorff D, Mano M, Rayner T, Head R. The cardiovascular protective role of docosahexaenoic acid. Eur J Pharmacol 1996, 300: 83-89.

[5] Kremer JM, Lawrence DA, Jubiz W, DiGiacomo R, Rynes R, Bartholomew LE, Sherman M. Dietary fish oil and olive oil supplementation in patients with rheumatoid arthritis. Clinical and immunologic effects. Arthritis Rheum 1990, 33: 810-820.

[6] Yokoyama A, Hamazaki T, Ohshita A, Kohno N, Sakai K, Zhao GD, Katayama H, Hiwada K. Effect of aerosolized docosahexaenoic acid 
in a mouse model of atopic asthma. Int Arch Allergy Immunol 2000, 123: 327-332.

[7] Das UN. Beneficial effect of eicosapentaenoic and docosahexaenoic acids in the management of systemic lupus erythematosus and its relationship to the cytokine network. Prostaglandins Leuktot Essent Fat Acids 1994, 51: 207-213.

[8] Pawlosky RJ, Salem N Jr. Ethanol exposure causes a decrease in docosahexaenoic acid and an increase in docosapentaenoic acid in feline brains and retinas. Am J Clin Nutr 1995 , 61: 1284-1289.

[9] Birch EE, Birch DG, Hoffman DR, Uauy R. Dietary essential fatty acid supply and visual acuity development. Invest Ophthamol Vis Sci 1992, 33: 3242-3253.

[10] De Caterina R, Caprioli R, Giannessi D, Sicari R, Galli C, Lazzerini G, Bernini W, Carr L, Rindi P. n-3 fatty acids reduce proteinuria in patients with chronic glomerular disease. Kidney Int 1993, 44: 843-850.

[11] Knapp HR. Omega-3 fatty acids in respiratory diseases: a review. J Am Coll Nutr 1995, 14: 18-23.

[12] Martinez M, Vazquez E, Garcia-Silva MT, Manzanares J, Bertram JM, Castello F, Mougan I. Therapeutic effects of docosahexaenoic acid ethyl ester in patients with generalized peroxisomal disorders. Am J Clin Nutr 2000, 71: 376S-385S.

[13] Tomobe YI, Morizawa K, Tsuchida M, Hibino H, Nakano Y, TanakaY. Dietary docosahexaenoic acid suppresses inflammation and immunoresponses in contact hypersensitivity reaction in mice. Lipids 2000, 35: 61-69.

[14] Grimminger F, Mayser P, Papavassilis C, Thomas M, Schlotzer E, Heuer KU, Fuhrer D, Hinsch KD, Walmrath D, Schill WB. A double-blind, randomized, placebo-controlled trial of n-3 fatty acid based lipid infusion in acute, extended guttate psoriasis. Rapid improvement of clinical manifestations and changes in neutrophil leukotriene profile. Clin Invest 1993, 71: 634-643.

[15] Freedman SD, Katz MH, Parker EM, Laposata M, Urman MY, Alvarez JG. A membrane lipid imbalance plays a role in the phenotypic expression of cystic fibrosis in cftr(-/-) mice. Proc Natl Acad Sci USA 1999, 96: 1399514000.

[16] Esteve-Comas M, Nunez MC, FernandezBanares F, Abad-Lacruz A, Gik A, Cabre E, Gonzales-Huix F, Bertran X, Gassull MA. Abnormal plasma polyunsaturated fatty acid pattern in non-active inflammatory bowel disease. Gut 1993, 34B: 1371-1373.
[17] Laugharne JD, Mellor JE, Peet M. Fatty acids and schizophrenia. Lipids 1996, 31 Suppl: S163-S165.

[18] Hibbeln JR, Salem N Jr. Dietary polyunsaturated fatty acids and depression: when cholesterol does not satisfy. Am J Clin Nutr 1995 , 62: 1-9.

[19] Lim SY, Suzuki H. Intakes of dietary docosahexaenoic acid ethyl ester and egg phosphatidylcholine improve maize learning ability in young and old mice. J Nutr 2000, 139: 16291632 .

[20] Menkes JH, Alter M, Steigleder GK, Weakley DR, Sung JH. A sex-linked recessive disorder with retardation of growth, peculiar hair and focal cerebral and cerebellar degeneration. Pediatrics 1962, 29: 764-779.

[21] Fevang P, Saav H, Hostmark AT. Dietary fish oils and long-term malaria protection in mice. Lipids 1995, 30: 437-441.

[22] Bernsohn J, Stephanides LM. Aetiology of multiple sclerosis. Nature 1967, 215: 821823.

[23] Wagner W, Nootbaar-Wagner U. Prophylactic treatment of migraine with gamma-linolenic and alpha linolenic acids. Cephalalgia 1997, 17: 127-130.

[24] Calder PC. Dietary modification of inflammation with lipids. Proc Nutr Soc 2002, 61: 345358.

[25] Kubo K, Sekine S, Saito M. Docosahexaenoic acid-containing phosphatidylethanolamine in the external layer of liposomes protects docosahexaenoic acid from 2,2'-azobis (2-aminopropane)dihydrochloride-mediated lipid peroxidation. Arch Biochem Biophys 2003, 410: 141-148.

[26] Mitchell DC, Litman BJ. Modulation of receptor signaling by phospholipid acyl chain composition. In: Mostofsky D, Yehuda S, Salem N Jr (Eds), Fatty Acids: Physiological and Behavioral Functions, Humana Press Inc, Totowa, NJ, 2001, p 23-40.

[27] Jump DB. Dietary polyunsaturated fatty acids and regulation of gene transcription. Curr Opin Lipidol 2002, 13: 155-164.

[28] Stillwell W. Docosahexaenoic acid and membrane lipid domains. Curr Organic Chem 2000, 4: 1169-1183.

[29] Salem NJ, Kim HY, Yergey J A. Docosahexaenoic acid: membrane function and metabolism. In: Simopolous AP, Kifer RR, Martin RE (Eds), Health Effects of Polyunsaturated Fatty Acids in Seafoods, Academic Press, New York, 1986, p 319-351.

[30] Breckenridge WC, Gombos G, Morgan IG. The lipid composition of adult rat brain 
synaptosomal membranes. Biochim Biophys Acta 1972, 266: 695-707.

[31] Neill AR, Masters CJ. Metabolism of fatty acids by bovine spermatozoa. J Reprod Fertil 1973, 34: 279-287.

[32] Poulos A, Darin-Bennet A, White IG. The phospholipids-bound fatty acids and aldehydes of mammalian spermatopzoa. Comp Biochem Physiol 1973, 46: 541-549.

[33] Wiegand RD, Anderson R E. Phospholipid molecular species of frog rod outer segment membranes. Exp Eye Res 1983, 37: 159-173.

[34] Anderson RE, Maude MB, Feldman GL. Lipids of ocular tissues. The phospholipids of mature bovine iris. Exp Eye Res 1970, 9: 281284.

[35] Miljanich GP, Sklar LA, White DL, Dratz EA. Disaturated and dipolyunsaturated phospholipids in the bovine retinal rod outer segment disk membrane. Biochim Biophys Acta 1979, 552: 294-306.

[36] Bell MV, Dick JR, Buda C. Molecular speciation of fish sperm phospholipids: large amounts of dipolyunsaturated phosphatidylserine. Lipids 1997, 32: 1085-1091.

[37] Van Meter AR, Ehringer WD, Stillwell W, Blumenthal E, Jenski LJ. Aged lymphocyte proliferation following incorporation and retention of dietary omega-3 fatty acids. Mechan Ageing Dev 1994, 75: 95-114.

[38] Robinson DR, Xu LL, Knoell CT, Tateno S, Olesiak W. Modification of spleen phospholipid fatty acid composition by dietary fish oil and by $n-3$ fatty acid ethyl esters. J Lipid Res 1993, 34: 1423-1434.

[39] Anderson RE, Sperling L. Lipids of ocular tissues. VII. Positional distribution of the fatty acids in the phospholipids of bovine retina rod outer segments. Arch Biochem Biophys 1971, 144: 673-677.

[40] Stubbs CD, Smith AD. The modification of mammalian membrane polyunsaturated fatty acid composition in relation to membrane fluidity and function. Biochim Biophys Acta 1984, 779: 89-137.

[41] Emmelot P, van Hoeven RP. Phospholipid unsaturation and plasma membrane organization. Chem Phys Lipids 1975, 14: 236-246.

[42] Salem N Jr, Bougnoux P. Asymmetry of phosphatidylethanolamine molecular species in the human lymphocyte plasma membrane. 24th Intl Conf Biochem Lipids 1983, p 44.

[43] Knapp HR, Hullin F, Salem N Jr. Asymmetric incorporation of dietary n-3 fatty acids into membrane aminophospholipids of human erythrocytes. J Lipid Res 1994, 35: 12831291.
[44] Dratz EA, Van Breeman JF, Kamps KM, Keegstra W, Van Bruggen EF. Two-dimensional crystallization of bovine rhodopsin. Biochim Biophys Acta 1985, 832: 337-342.

[45] Holte LL, Peter SA, Sinnwell TM, Gawrisch K. ${ }^{2} \mathrm{H}$ nuclear magnetic resonance order profiles suggest a change of molecular shape for phospahtidylcholines containing a polyunsaturated acyl chain. Biophys J 1995, 68: 23962403.

[46] Eldho NV, Feller SE, Tristram-Nagle S, Polozov IV, Gawrisch K. Polyunsaturated docosahexaenoic vs. docosapentaenoic acid - differences in lipid matrix properties from the loss of one double bond. J Am Chem Soc 2003, 125: 6409-6421.

[47] Saiz L, Klein ML. Structural properties of a highly polyunsaturated lipid bilayer from molecular dynamics simulations. Biophys J 2001, 81: 204-216.

[48] Feller SE, Gawrisch K, Woolf TB. Rhodopsin exhibits a preference for solvation by polyunsaturated docosahexaenoic acid. J Amer Chem Soc 2002, 125: 4434-4435.

[49] Huber T, Rajamoorthi K, Kurze VF, Beyer K, Brown MF. Structure of docosahexaenoic acid-containing phospholipid bialyers as studied by ${ }^{2} \mathrm{H}$ NMR and molecular dynamics simulations. J Amer Chem Soc 2002, 124: 298309.

[50] Straume M, Litman BJ. Equilibrium and dynamic structure of large, unilamellar, unsaturated acyl chain phosphatidylcholine vesicles. Higher order analysis of 1,6-diphenyl-1,3,5-hexatriene and 1-[4-(trimethylammonio)phenyl]-6-phenyl-1,3,5-hexatriene anisotropy decay. Biochemistry 1987, 26: 5113-5120.

[51] Stubbs CD. The structure and function of docosahexaenoic acid in membranes. In: Sinclair A, Gibson R (Eds), Essential Fatty Acids and Eicosanoids, AOCS, Champaign, Illinois, 1992, p 116-121.

[52] Salem N Jr, Niebylski CD. The nervous system has an absolute molecular species requirement for proper function. Mol Membrane Biol 1995, 12: 131-134.

[53] Mitchell DC, Litman BJ. Molecular order and dynamics in bilayers consisting of highly polyunsaturated phospholipids. Biophys J 1998, 74: 879-891.

[54] Kamada T, Yamashita T, Baba Y, Kai M, Setoyama S, Chuman Y, Otsuji S. Dietary sardine oil increases erythrocyte membrane fluidity in diabetic patients. Diabetes 1986, 35: 604-611.

[55] Ernst E. Effects of n-3 fatty acids on blood rheology. J Int Med 1994, 225: 129-132. 
[56] Brown ER, Subbaiah PV. Differential effects of eicosapentaenoic acid and docosahexaenoic acid on human skin fibroblasts. Lipids 1994, 29: 825-829.

[57] Calder PC, Yaqoob P, Harvey DJ, Watts A, Newsholme E.A. Incorporation of fatty acids by concanavalin A-stimulated lymphocytes and the effect on fatty acid composition and membrane fluidity. Biochem J 1994, 300: 509-518.

[58] Sobajima T, Tamiya-Koizumi K, Ishihara H, Kojima K. Effects of fatty acid modification of ascites tumor cells on pulmonary metastasis in rat. Jpn J Cancer Res 1986, 77: 657-663.

[59] Yorek M, Leeney E, Dunlap J, Ginsberg B. Effect of fatty acid composition on insulin and IGF-I binding in retinoblastoma cells. Invest Ophthalmol Vis Sci 1989, 30: 2087-2092.

[60] Clamp AG, Ladha S, Clark DC, Grimble RF, Lund EK. The influence of dietary lipids on the composition and membrane fluidity of rat hepatocyte plasma membranes. Lipids 1997, 32: $179-184$

[61] Wahnon R, Cogan U, Mokady S. Dietary fish oil modulates the alkaline phosphatase activity and not the fluidity of rat intestinal microvillus membrane. J Nutr 1992, 122: 10771084.

[62] Popp-Snijders C, Schouten JA, Van Blitterswijk WJ, Van Der Veen EA. Changes in membrane lipid composition of human erythrocytes after dietary supplementation of $(n-3)$ polyunsaturated aftty acids. Maintenance of membrane fluidity. Biochim Biophys Acta 1986, 854: 31-37.

[63] Gibney MJ, Bolton-Smith C. The effect of a dietary supplement of $n-3$ polyunsaturated fat on platelet lipid composition, platelet function and platelet plasma membrane fluidity in healthy volunteers. Br J Nutr 1988, 60: 5-12.

[64] Treen M, Uauy RD, Jameson DM, Thomas VL, Hoffman DR. Effect of docosahexaenoic acid on membrane fluidity and function in intact cultured Y-79 retinoblastoma cells. Arch Biochem Biophys 1992, 294: 564-570.

[65] Stillwell W, Jenski LJ, Crump FT, Ehringer W. Effect of docosahexaenoic acid on mouse mitochondrial membrane properties. Lipids 1997, 32: 497-506.

[66] Niebylski CD, Salem N Jr. A calorimetric investigation of a series of mixed-chain polyunsaturated phopsphatidylcholines: effects of sn-2 chain length and degree of unsaturation. Biophys J 1994, 67: 2387-2393.

[67] Dratz EA, Deese AJ. The role of docosahexaenoic acid in biological membranes: Examples from photoreceptors and model membrane bilayers. In: Simopolous AP, Kifer RR,
Martin RE (Eds), Health Effects of Polyunsaturated Fatty Acids in Seafoods, Academic Press, New York, 1986, p 319-351.

[68] Smaby JM, Momsen MM, Brockman HL, Brown RE. Phosphatidylcholine acyl unsaturation modulates the decrease in interfacial elasticity induced by cholesterol. Biophys J 1997, 73: 1492-1505.

[69] Koenig BW, Strey HH, Gawrisch K. Membrane lateral compressibility determined by NMR and x-ray diffraction: effect of acyl chain polyunsaturation. Biophys J 1997, 73 : 1954-1966.

[70] Epand RM. Lipid polymorphism and proteinlipid interactions. Biochim Biophys Acta 1998, 1367: 353-368.

[71] Gruner SM. Intrinsic curvature hypothesis for biomembrane lipid composition: a role for nonbilayer lipids. Proc Natl Acad Sci USA 1985, 82: 3665-3669.

[72] Killian JA. Hydrophobic mismatch between proteins and lipids in membranes. Biochim Biophys Acta 1998, 1376: 401-415.

[73] Litman BJ, Mitchell DC. A role for phospholipid polyunsaturation in modulating membrane protein function. Lipids 1996, 31: S193-S197.

[74] Mitchell DC, Straume M, Litman BJ. Role of sn-1-saturated, sn-2-polyunsaturated phospholipids in control of membrane receptor conformational equilibrium: effects of cholesterol and acyl chain unsaturation on the metarhodopsin I/metarhodopsin II equilibrium. Biochemistry 1992, 31: 662-670.

[75] Brown MF. Modulation of rhodopsin function by properties of the membrane bilayer. Chem Phys Lipids 1994, 73: 159-180.

[76] Mitchell DC, Litman BJ. Phospholipid acyl chain unsaturation determins cholesterol effects on rhodopsin photoactivation. Biophys J 1997, 72: A310.

[77] Hendriks T, Klompmakers AA, Daemen FJM, Bonting SL. Biochemical aspects of the visual process. XXXII. Movement of sodium ions through bilayers composed of retinal and rod outer segment lipids. Biochim Biophys Acta 1976, 433, 271-281.

[78] Demel RA, Geurts van Kessel WSM, Van Deenan LLM. The properties of polyunsaturated lecithins in monolayers and liposomes and the interactions of these lecithins with cholesterol. Biochim Biophys Acta 1972, 266: $26-40$.

[79] Stillwell W, Ehringer WD, Jenski LJ. Docosahexaenoic acid increases permeability of lipid vesicles and tumor cells. Lipids 1993, 28 : 103-108. 
[80] Huster D, Arnold K, Gawrisch K. Influence of docosahexaenoic acid and cholesterol on lateral lipid organization in phospholipid mixtures. Biochemistry 1998, 37: 17299_ 17308.

[81] Brand MD, Couture P, Hulbert AJ. Liposomes from mammalian liver mitochondria are more polyunsaturated and leakier to protons than those from reptiles. Comp Biochem Physiol 1994, 108B: 181-188.

[82] Newmeyer DD, Ferguson-Miller S. Mitochondria: releasing power for life and unleashing the machineries of death. Cell 2003, 112: 481-490.

[83] Ahkong QF, Fisher D, Tampion W, Lucy JA. The fusion of erythrocytes by fatty acids, esters, retinol and alpha-tocopherol. Biochem J 1973, 136: 147-155.

[84] Meers P, Hong K, Papahadjopoulos D. Free fatty acid enhancement of cation-induced fusion of liposomes: synergism with synexin and other promoters of vesicle aggregation. Biochemistry 1988, 27: 6784-6794.

[85] Ehringer W, Belcher D, Wassall SR, Stillwell W. A comparison of the effects of linolenic

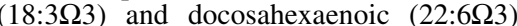
acids on phospholipid bilayers. Chem Phys Lipids 1990, 54: 79-88.

[86] Pascale AW, Ehringer WD, Stillwell W, Sturdevant LK, Jenski LJ. Omega-3 fatty acid modification of membrane structure and function. II. Alteration by docosahexaenoic acid of tumor cell sensitivity to immune cytolysis. Nutr Cancer 1993, 19: 147-157.

[87] Jenski LJ, Zerouga M, Stillwell W. Omega3 fatty acid containing liposomes in cancer therapy. Proc Soc Exp Biol Med 1995, 210: 227-233.

88] Kafrawy O, Zerouga M, Stillwell W, Jenski LJ. Docosahexaenoic acid in phosphatidylcholine mediates cytotoxicity more effectively then other omega-3 and omega- 6 fatty acids. Cancer Lett 1998, 132: 23-29.

[89] Jenski LJ, Bowker GM, Johnson MA, Ehringer WD, Fetterhoff T, Stillwell W. Docosahexaenoic acid-induced alteration of THY - 1 and CD8 expression on murine splenocytes. Biochim Biophys Acta 1995, 1236: 39-50.

[90] Stillwell W, Wassall SR, Dumaual AC, Ehringer WD, Browning CW, Jenski LJ. Use of merocyanine (MC540) in quantifying lipid domains and packing in phospholipid vesicles and tumor cells. Biochim Biophys Acta 1993, 1146: 136-144.

[91] Zerouga M, Jenski LJ, Booster S, Stillwell W. Can docosahexaenoic acid inhibit metas- tasis by decreasing deformability of the tumor cell plasma membrane? Cancer Lett 1997, 119: 163-168.

[92] Ellens H, Siegel DP, Alford D, Yeagle PL, Boni L, Lis LJ, Quinn PJ, Bentz J. Membrane fusion and inverted phase. Biochemistry 1989, 28: 3692-3703.

[93] Williams EE, Jenski LJ, Stillwell W. Docosahexaenoic acid (DHA) alters the structure and composition of membranous vesicles exfoliated from the surface of a murine leukemia cell line. Biochim. Biophys. Acta 1998, 1371: 351-362.

[94] Armstrong VT, Brzustowicz MR, Wassall SR, Jenski LJ, Stillwell W. Rapid flip-flop in polyunsaturated (docosahexaenoate) phospholipid membranes. Arch Biochem Biophys 2003, 414: 74-82.

[95] Edidin M. Patches and fences: probing for plasma membrane domains. J Cell Sci 1993, Suppl 17: 165-169.

[96] Edidin M. Shrinknig patches and slippery rafts: scales of domains in the plasma membrane. Trends Cell Biol 2001, 11: 493-496.

[97] Edidin M. The state of lipid rafts: from model membranes to cells. Annu Rev Biophys Biomol Struct 2003, 32: 257-283.

[98] Singer SJ, Nicolson GL. The fluid mosaic model of the structure of cell membranes. Science 1971, 175: 720-731.

[99] Simons K, Ikonnen E. Functional rafts in cell membranes. Nature 1997, 389: 569-572.

[100] Brown DA, London E. Structure and function of sphingolipid- and cholesterol-rich membrane rafts. J Biol Chem 2000, 275: 1722117224.

[101] Finegold L (Ed). Cholesterol in Membrane Models. CRC Press, Boca Raton, FL, 1993.

[102] Shinitzky M. Membrane fluidity and cellular function. In: Shinitzky M (Ed), Physiology of Membrane Fluidity, CRC Press, Boca Raton, FL, 1984, p 1-51.

[103] Evans RW, Tinoco J. Monolayers of sterols and phosphatidylcholines containing a 20carbon chain. Chem Phys Lipids 1978, 22: 207-220.

[104] Zerouga M, Jenski LJ, Stillwell W. Comparison of phosphatidylcholines containing one or two docosahexaenoic acyl chains on properties of phospholipid monolayers and bilayers. Biochim Biophys Acta 1995, 1236: 266 272.

[105] Niu SL, Litman BJ. Determination of membrane cholesterol partition coefficient using a lipid vesicle-cyclodextrin binary system: 
effect of phospholipid acyl chain unsaturation and head group composition. Biophys $\mathbf{J}$ 2002, 83: 3406-3415.

[106] Ghosh D, Williams MA, Tinoco J. The influence of lecithin structure on their monolayer behavior and interactions with cholesterol. Biochim Biophys Acta 1973, 291: 351-362.

[107] Stillwell W, Dallman T, Dumaual AC, Crump FT, Jenski LJ. Cholesterol vs. $\alpha$-tocopherol: effect on properties of bilayers made from heteroacid phosphatidylcholines. Biochemistry 1996, 35: 13353-13362.

[108] Kariel N, Davidson E, Keough KMW. Cholesterol does not remove the gel-liquid crystalline phase transition of phosphatidylcholines containing two polyenoic acyl chains. Biochim Biophys Acta 1991, 1062: 70-76.

[109] Hernandez-Borrell J, Keough KMW. Heteroacid phosphatidylcholines with different amounts of unsaturation respond differently to cholesterol. Biochim Biophys Acta 1993, 1153: 277-282.

[110] Davis JH. The molecular dynamics, orientational order, and thermodynamic phase equilibria of cholesterol/phosphatidylcholine mixtures: ${ }^{2} \mathrm{H}$ nuclear magnetic resonance. In: Finegold L (Ed), Cholesterol in Model Membranes, Boca Raton, CRC Press, Florida, 1993, p 67-135.

[111] Mitchell DC, Litman BJ. Effect of cholesterol on molecular order and dynamics in highly polyunsaturated phospholipid bilayers. Biophys J 1998, 75: 896-908.

[112] Jackman CS, Davis PJ, Morrow MR, Keough KMW. Effect of cholesterol on the chainordering transition of 1-palmitoyl-2-arachidonyl phosphatidylcholine. J Phys Chem B 1999, 103: 8830-8836.

[113] Brzustowicz MR, Stillwell W, Wassall SR. Molecular organization of cholesterol in polyunsaturated membranes: a solid state ${ }^{2} \mathrm{H}$ NMR investigation. FEBS Lett 1999, 415: 197-202.

[114] Brzustowicz MR, Cherezov V, Zerouga M, Caffrey M, Stillwell W, Wassall SR. Controlling membrane cholesterol content. A role for polyunsaturated (docosahexaenoate) phospholipids. Biochemistry 2000, 41: 1250912519.

[115] Brzustowicz MR, Cherezov V, Caffrey M, Stillwell W, Wassall SR. Molecular organization of cholesterol in polyunsaturated membranes: microdomain formation. Biophys J 2002, 82: 285-298.

[116] Shaikh SR, Cherezov V, Caffrey M, Stillwell W, Wassall SR. Interaction of cholesterol with a docosahexaenoic acid-containing PE:
Trigger for microdomain/raft formation? Biochemistry 2003, 42: 12028-12037.

[117] Shaikh SR, Brzustowicz MR, Gustafson N, Stillwell W, Wassall SR. Monounsaturated PE does not phase separate form the lipid raft molecules sphingomyelin and cholesterol: role for polyunsaturation? Biochemistry 2002, 41: 10593-1060.

[118] Pitman MC, Suits F, MacKerell AD Jr, Feller SE. Molecular organization of saturated and polyunsaturated fatty acids in a phosphatidylcholine bilayer containing cholesterol. Biochemistry 2004, 43: 15318-15328.

[119] Van Dijck PW. Negatively charged phospholipids and their position in the cholesterol affinity sequence. Biochim Biophys Acta 1979, 555: 89-101.

[120] Simons K, Vaz WL. Model systems, lipid rafts, and cell membranes. Annu Rev Biophys Biomol Struct 2004, 33: 269-295.

[121] Mouritsen OG. Self-assembly and organization of lipid-protein membranes. Curr Opin Coll Int Sci 1998, 3: 78-87.

[122] Shaikh SR, Dumaual AC, Jenski LJ, Stillwell $\mathrm{W}$. Lipid phase separation in phospholipid bilayers and monolayers modeling the plasma membrane. Biochim Biophys Acta 2001, 1512: 317-328.

[123] Pasenkiewicz-Gierula M, Subczynski WK, Kusumi A. Influence of phospholipid unsaturation on the cholesterol distribution in membranes. Biochimie 1991, 73: 1311-1316.

[124] Niebylski CD, Litman BJ. Lateral phase heterogeneiety in dipolyunsaturated and disaturated phospholipid bilayers monitored with novel pyrene-labeled phospholipids. Biophys J 1997, 72: A305.

[125] Shaikh SR, Dumaual AC, Castillo A, LoCascio D, Siddiqui RA, Stillwell W, Wassall SR. Oleic and docosahexaenoic acid differentially phase separate from lipid raft molecules: A comparative NMR, DSC, AFM and detergent extraction study. Biophys J 2004, 87: 1752-1766.

[126] Jenski LJ, Caldwell L, Jiricko P, Scherer J, Stillwell W. DHA-Facilitated Membrane Protein Clustering and T-Cell Activation. In: Riemersma RA, Armstrong RA, Kelly RW, Wilson R, Essential Fatty Acids and Eicosanoids, AOCS Press, Champaign, IL, 1998, p 191-196.

[127] Polozova A, Litman BJ. Cholesterol recruitment of di-22:6 PC by a $\mathrm{G}$ protein coupled receptor into lateral domains. Biophys $\mathrm{J}$ 2000, 79: 2632-2643. 
[128] Litman BJ, Niu SL, Polozova A, Mitchell DC. The role of docosahexaenoic acid containing phospholipids in modulating $G$ protein-coupled signaling pathways: visual transduction. J Molec Neurosci 2001, 16: 237-242; discussion 279-284.

[129] Salem N Jr, Litman B, Kim HY, Gawrisch K. Mechanisms of action of docosahexaenoic acid in the nervous system. Lipids 2001, 36: 945-959.

[130] Fontaine RN, Harris RA, Schroeder F. Aminophospholipid asymmetry in murine synaptosomal plasma membrane. J Neurochem 1980, 34: 269-277.

[131] Kuypers FA, Abraham S, Lubin B, Chiu D. Diet-induced asymmetry of the phosphatidylcholine fatty acyl composition in rat erythrocyte membranes. J Lab Clin Med 1988, 111: 529-536.

[132] Sweet WD, Schroeder F. Polyunsaturated fatty acids alter sterol transbilayer domains in LM fibroblast plasma membrane. FEBS Lett 1988, 229: 188-192.

[133] Schroeder F, Jefferson JR, Kier AB, Knittel J, Scallen TJ, Wood WG, Hapala I. Membrane cholesterol dynamics: cholesterol domains and kinetic pools. Proc Soc Exp Biol Med 1991, 196: 235-252.

[134] Lange Y, Dolde J, Steck TL. The rate of transmembrane movement of cholesterol in the human erythrocyte. J Biol Chem 1981, 256 : 5321-5323.

[135] Schroeder F, Frolov AA, Murphy EJ, Atshaves BP, Jefferson JR, Pu L, Wood WG, Foxworth WB, Kier AB. Proc Soc Exp Biol Med 1996, 213: 150-177.

[136] Van Dijck PMW, De Kruijff BB, Van Deenen LLM, de Gier J, Demel RA. Preference of cholesterol for phosphatidylcholine in mixed phosphatidylcholine-phosphatidylethanolamine bilayers. Biochim Biophys Acta 1976, 455: 576-587.

[137] Leventis R, Silvius JR. Use of cyclodextrins to monitor transbilayer movement and differential lipid affinities of cholesterol. Biophys J 2001, 81: 2257-2267.

[138] Steck TL, Ye J, Lange Y. Probing red cell membrane cholesterol movement with cyclodextrin. Biophys J 2002, 83: 2118-2125.

[139] Muller P, Herrmann A. Rapid trans-bilayer movement of spin-labeled steroids in human erythrocytes and in liposomes. Biophys $\mathbf{J}$ 2002, 82: 1418-1428.
[140] Dusserre E, Pulcini T, Bourdillon MC, Ciavatti, M, Berthezene F. Omega-3 fatty acids in smooth muscle cell phospholipids increase membrane cholesterol efflux. Lipids 1995, 30: $35-41$.

[141] Slater SJ, Kelly MB, Taddeo FJ, Ho C, Rubin E, Stubbs CD. The modulation of protein kinase $\mathrm{C}$ activity by membrane lipid bilayer structure. J Biol Chem 1994, 269: 48664871.

[142] Epand RM. Effect of PKC modulators on membrane properties. In: Lester DS and Epand RM (Eds), Protein Kinase C. Current Concepts and Future Perspectives, Ellis Horwood, Chichester, England, 1992, p 135156.

[143] Mosior M, Golini ES, Epand RM. Chemical specificity and physical properties of the lipid bilayer in the regulation of protein kinase $\mathrm{C}$ by anionic phospholipids: evidence for the lack of a specific binding site for phosphatidylserine. Proc Natl Acad Sci USA 1996, 93 : 1907-1912.

[144] Giorgione J, Epand RM, Buda C, Farkas T. Role of phospholipids containing docosahexaenoyl chains in modulating the activity of protein kinase C. Proc Natl Acad Sci USA 1995, 92: 9767-9770.

[145] Poling JS, Karanian JW, Salem N Jr, Vicini S. Time- and voltage-dependent block of delayed rectifier potassium channels by docosahexaenoic acid. Mol Pharmacol 1995 , 47: 381-390.

[146] Poling JS, Vicini S, Rogawski MA, Salem N Jr. Docosahexaenoic acid block of neuronal voltage-gated $\mathrm{K}^{+}$channels: subunit selective antagonism by zinc. Neuropharmacol 1996, 35: 969-982.

[147] Pepe S, Bogdanov K, Hallaq H, Spurgeon H, Leaf A, Lakatta E. Omega 3 polyunsaturated fatty acid modulates dihydropyridine effects on L-type $\mathrm{Ca}^{2+}$ channels, cytosolic $\mathrm{Ca}^{2+}$, and contraction in adult rat cardiac myocytes. Proc Natl Acad Sci USA 1994, 91: 88328836.

[148] Xiao YF, Gomez AM, Morgan JP, Lederer WJ, Leaf A. Suppression of voltage-gated L-type $\mathrm{Ca}^{2+}$ currents by polyunsaturated fatty acids in adult and neonatal rat ventricular myocytes. Proc Natl Acad Sci USA 1997, 94: 4182-4186.

[149] Hasler CM, Trosko JE, Bennink MR. Incorporation of $n-3$ fatty acids into WB-F344 cell phospholipids inhibits gap junctional intercellular communication. Lipids 1991, 26: 788-792. 
[150] Jenski LJ, Nanda PK, Jiricko P, Stillwell W. Docosahexaenoic-containing phosphatidylcholine affects the binding of monoclonal antibodies to purified $\mathrm{K}^{\mathrm{b}}$ reconstituted into liposomes. Biochim Biophys Acta 2000, 1467: 293-306

[151] Cohen GM, Sun XM, Snowden RT, Dinsdale D, Skilleter DN. Key morphological features of apoptosis occur in the absence of internucleosomal DHA fragmentation. Biochem $\mathbf{J}$ 1987, 286: 331-334.

[152] Van den Eijnde SM, Boshart L, Reuteingsperger CPM, DeZeeuw CI, Vermeij-Keers C. Phosphatidylserine plasma membrane asymmetry in vivo: a pancellular phenomenon which alters during apoptosis, Cell Death Differ 1997, 4: 311-316.

[153] Williamson P, Schlegel RA. Transbilayer phospholipid movement and the clearance of apoptotic cells. Biochem Biophys Acta 2002, 1585: 53-63.

[154] Diep QN, Intengan HD, Schiffrin EL. Endothelin-1 attenuates $\omega$-3 fatty acidinduced apoptosis by inhibition of caspase 3 . Hypertension 2000, 35: 287-291.

[155] Shiina T, Terano T, Saito J, Tamura Y, Yoshida S. Eicosapentaenoic acid and docosapentaenoic acid surpress the proliferation of vascular smooth muscle cells. Atherosclerosis 1993, 104: 95-103.

[156] Calviello G, Palozza P, Piccioni E, Maggioano N, Frattucci A, Fmceschelli P, Bartoli GM. Dietary supplementation with eicosapentaenoic and docosapentaenoic acid inhibits growth of Morris hepatocarcinoms 3924A in rats: effects on proliferation and apoptosis. Int J Cancer 1998, 75: 699-705.

[157] Minami M, Noguchi M. Effects of low-dose eicosapentsenoic acid and docosapentaenoic acid and vdietary fat on the incidence, growth and cell kinetics of mammory carcinomas in rats. Oncology 1996, 53: 398-505.

[158] Tsai WS, Nagawa H, Kaizaki S, Tsuruo T, Muto T. Inhibitory effects of $n-3$ polyunsaturated fatty acids on sigmoid cancer transformants. J Gastroenterol 1998, 33: 206-212.

[159] Hatala MA, Rayburn J, Rose DP. Comparison of linoleic and eicosapentaenoic acid incorporation into human breast cancer cells. Lipids 1994, 29: 831-837.

[160] Siddiqui RA, Jenski LJ, Neff K, Harvey K, Kovacs RJ, Stillwell W. Docosahexaenoic acid induces apoptosis in Jurcat cells by a protein phosphate-mediated pathway. Biochim Biophys Acta 2001, 1499: 265-275.
[161] Siddiqui RA, Jenski LJ, Wiesehan JD, Hunter MV, Kovacs RJ, Stillwell W. Prevention of docosahexaemoic acid-induced cytotoxicity by phosphatidic acid in jurkat leukemic cells: The Role of Protein Phosphatase-1. Biochim Biophys Acta 2001, 1541: 188-200.

[162] Connolly JM, Gilhooly EM, Rose DP. Effects of reduced dietary linoleic acid intake, alone or combined with an algal source of docosahexaenoic acid, on MDAMB-231 breast cancer cell growth and apoptosis in nude mice. Nutr Cancer 1999, 35 : $44-49$.

[163] Siddiqui RA, Shaikh SR, Sech LA, Yount HR, Stillwell W, Zaloga GP. Omega-3 fatty acids: health benefits and cellular mechanisms of action. Mini-Rev Med Chem 2004, 4: 859-871.

[164] Wu M, Harvey KA, Ruzmetov N, Welch ZR, Sech L, Jackson K, Stillwell W, Zaloga GP, Siddiqui RA. Omega-3 polyunsaturated fatty acids attenuate cancer growth through activation of a neural sphingomyelinase-mediated pathway. Int J Cancer 2005, 117: 340348.

[165] Jayadev S, Liu B, Bielawaka AE, Lee JY, Nazaire F, Pushkareva M, Obeid LM, Hannun YA. Role for ceramide in cell cycle arrest. J Biol Chem 1995, 270: 2047-2052.

[166] Rose DP, Connolly JM. Antiangiogenicity of docosahexaenoic acid and its role in the suppression of breast cancer cell growth in nude mice. Int J Oncol 1999, 15: 1011-1015.

[167] Akbar M, Kim HY. Protective effects of docosahexaenoic acid in staurosporineinduced apoptosis: involvement of phosphatidylinositol-3 kinase pathway. J Neurochem 2002, 82: 655-665.

[168] Kim HY, Akbar M, Lau A, Edsall L. Inhibition of neuronal apoptosis by docosahexaenoic acid (22:6n-3): role of phosphatidylserine in antiapoptotic effect. J Biol Chem 2000, 275: 35215-35223.

[169] Kishida E, Yano M, Kasahara M, Masuzawa Y. Distinctive inhibitory activity of docosahexaenoic acid against sphingosine-induced apoptosis. Biochim Biophys Acta 1998, 1391: 401-408.

[170] Huang J, Buboltz JT, Feigenson GW. Maximum solubility of cholesterol in phosphatidylcholine and phosphatidylethanolamine bilayers. Biochim Biophys Acta 1999, 1417: 89-100. 